tested. Wide scope public health influencers exist in several forms, including education, stakeholder partnership and legislation. Collectively, the complexity of this problem indicates that public health strategies for this condition require a multidisciplinary and multifaceted approach that should be sustained over a period of time. Musculoskeletal models of care and frameworks that have been developed by multiple stakeholders at statewide levels have been shown to be of value. This talk will describe the process of developing such a framework through surveys and focus groups for the state of Western Australia.

Methods Key stakeholders for WMSDs in WA were initially identified and placed in a network database. These comprised of government agencies, employer and employee groups, special interest groups, professional bodies, key academics, industry peak bodies and the insurance sector. Surveys and focus groups were held across Western Australia over a 3 month period. The primary aim of the qualitative data collection was to gain an understanding of the views of key stakeholders in relation to the prevention and management of work-related musculoskeletal, particularly their believes of the risk factors, facilitators and barriers for success and their views of current policy and legislation associated with this condition.

Results Information collected demonstrated that a high proportion of key stakeholders viewed this as a significant state-wide issue. The views of key stakeholders in relation to risk factors, barriers and facilitators for the prevention and management of this condition varied across the stakeholder groups and trends could be identified within and between stakeholder groups. Results show the interconnection between these stakeholder groups and the potential value of systematic and organised information sharing and staged collaborative intervention.

Conclusion The development of a state-wide framework for WMSDs requires an understanding of the evidence behind the multifaceted interventions, and a staged and consultative approach to achieve ownership and confidence in the stakeholders and implementers of the framework.

\section{HEALTH OF WORKING CHILDREN: BEYOND WORKPLACE HAZARDS}

Iman Nuwayhid. Professor and Dean, Faculty of Health Sciences, American University of Beirut, Beirut, Lebanon

\subsection{6/oemed-2018-ICOHabstracts. 25}

Introduction Globally, hundreds of millions of children younger than 18 years of age are reported to be working in dangerous jobs and worst forms of child labour with exposure to a myriad of hazards. However, in our assessment of the health and wellbeing of these children, we invariably tend to dismiss the factors that have pushed these children in the first place to work, especially in hazardous occupations. This presentation puts child labour in perspective and explores hazards beyond the workplace.

Methods A review of the relevant literature on exposures and health of working children and a reflection on my personal experience and observations of the issue of child labour in Lebanon.

Results Many papers have been published on the exposure of working children to physical, chemical, biological, safety, and psychological hazards at the workplace. There is a dearth of research in the health domain on the complexity of child labour and its social and political determinants, especially in the context of war and conflicts.
Discussion Are we realistic about our goals and targets in the journey to eliminate or control child labour? Who are our partners on this path? How do we deal with child labour in the context of refugees and conflicts?

\section{GLOBAL WARMING AND OCCUPATIONAL HEAT AND HOT ENVIRONMENT STANDARD IN THAILAND}

Wantanee Phanprasit, Kannikar Rittaprom, Vorakamol Boonyayothin. Dept. of Occupational Health and Safety, Faculty of Public Health, Mahidol University, Bangkok, Thailand

\subsection{6/oemed-2018-ICOHabstracts.26}

Introduction The current occupational exposure to heat and hot environment standard of Thai law was issued in 2006. The wet bulb globe temperature (WBGT) index was defined for 3 workload levels without a work-rest regimen. To assess heat exposure according to the law, workload and WBGT is monitored for 2 hours during the hottest period of the day in summer. As has been predicted, global warming could significantly impact labour capacity and productivity in Southeast Asian countries. Thus, this study aimed to explore whether the occupational standard could protect outside workers focusing on construction workers in Thailand.

Methods This cross-sectional study included 18 medium and small construction sites and involved 90 heat acclimatised construction workers. Most wore cotton long sleeve shirts and pants. Heart rate (HR) and Aural (tympanic) temperature of the participants were recorded continuously for 2 hours. Exposure data comprised relative humidity, wind velocity and WBGT, including dry bulb, wet bulb and globe temperatures, were monitored and the participants' workloads were estimated, simultaneously with the collection of physiological and environmental data, i.e. March to June. In addition a questionnaire was used to collect data of the participants.

Result WBGT ranged from $24.35-34.18^{\circ} \mathrm{C}$, and 47 participants were exposed to WBGT exceeding the standard. Average air velocity and $\mathrm{RH}$ were $1.11 \mathrm{~m} / \mathrm{s}$ and $35.77 \%$, respectively. The range of average core body temperature and HR for 3 levels of workload were $36.60-39.4^{\circ} \mathrm{C}, 70-97 \mathrm{bpm}, 36.62-39.58^{\circ} \mathrm{C}$, $80-126 \mathrm{bpm}$ and $37.04-40.08^{\circ} \mathrm{C}, 82-127 \mathrm{bpm}$ respectively. Core body temperature of 29 of 47 participants exposed to heat above the standard exceeded $38^{\circ} \mathrm{C}$, among these 11 had symptoms of heat related illness. In all, 18 participants were exposed to heat below the standard but their core body temperatures were higher than $38^{\circ} \mathrm{C}$.

Discussion The weather was hot and dry with occasional good air movement. However, 32\% of construction workers worked in high risk conditions (WBGT above the standard). Furthermore, 18 (20\%) participants worked in an environment below the standard but their body core temperatures exceeded $38^{\circ} \mathrm{C}$. Thus, this group of workers was not protected by the standard.

\section{HEALTHY AGEING, HEALTHY WORK: A GLOBAL PERSPECTIVE ON THE HOME CARE WORKFORCE}

Margaret Quinn. University of Massachusetts Lowell, Lowell, USA

\subsection{6/oemed-2018-ICOHabstracts. 27}

Introduction By 2030 one billion people worldwide will be 65 years of age or older. While populations in industrially- 
developed countries are ageing rapidly, the most dramatic increases are occurring in developing countries. Because most elders prefer to be cared for at home, these profound demographic shifts are driving a global need for home care (HC) at an unprecedented rate. As a result, $\mathrm{HC}$ aide jobs are among the fastest growing occupations and yet their occupational safety and health (OSH) experience is nearly invisible. The Safe Home Care Project at the University of Massachusetts, Lowell USA, funded by the US National Institute for Occupational Safety and Health, was established to protect and promote the OSH of the HC workforce.

Methods We used mixed methods ranging from focus groups to large scale OSH questionnaire surveys, microbiology field studies, and laboratory experimental studies of chemical, biologic, and biomechanical hazards. These studies were performed among HC aides and elders who are $\mathrm{HC}$ recipients.

Results HC aides experience numerous OSH hazards similar to hospitals and nursing homes: back injuries from patient lifting; needlestick injuries; respiratory irritant exposures from cleaning and disinfecting; and serious encounters with violence from patients or family members. Aides also experience hazards not seen in institutional settings: exposure to secondhand smoke, risk of fire from patients smoking cigarettes while on oxygen, patients re-using needles for injections and storing them improperly, and lack of medical equipment for patient lifting. Overall, we found that high quality care delivery depends significantly on HC aide safety.

Discussion $\mathrm{HC}$ aides need $\mathrm{OSH}$ protections. Despite $\mathrm{OSH}$ challenges, the great majority of aides report high job satisfaction due to meaningful relationships with patients and families and to the relative autonomy compared to institutional care work. Interventions should enhance these beneficial aspects of $\mathrm{HC}$ work as well as improve $\mathrm{OSH}$.

\section{SEED SAFETY AND HEALTH WHEN RUSHING TO HELP} ${ }^{1,2,3}$ Michael Riediker, ${ }^{4}$ Magda Stepanyan. ${ }^{1}$ IOM (Institute of Occupational Medicine)
Singapore, Singapore, Singapore; ${ }^{2}$ School of Materials Science and Engineering, Nanyang
Technological University, Singapore, Singapore; ${ }^{3}$ Institut universitaire romand de santé au
travail, University of Lausanne, Epalinges, Switzerland; ${ }^{4}$ The Risk Society, Den Hague, The
Netherlands

\subsection{6/oemed-2018-ICOHabstracts.28}

Introduction Helping local populations develop economic independence is an important aspect of international development programming, and can be critical for longer-term resilience building after major natural disasters. When teaching new skills and methods, one needs to make sure that:

1. those teaching the skills stay healthy while on site, and

2. that the new workforce learns about the essential elements of workplace safety and health (WSH) so that they stay healthy while becoming economically more stable.

Methods The principle to keep both, trainers and trainees safe and healthy during a training and later on is universal. However, many of these interventions happen in ill-controlled situations with many other concerns such as security and administrative challenges related to the exceptional situation. Furthermore, many well-intending teams perceive the situations as 'emergency'. Combined with the hesitance to be 'better treated' than the locals, this can lead to them accepting and taking more risks than they would accept at home.
Result Trainers need to plan how to recognise and teach good safety and health practices in situations where they don't have access to sophisticated or expensive measures. They can set an example to the local population by using WSH methods that are adapted to the specific risks of the solutions. They need to be simple and cheap so that they can later be applied by the locals. Trainers need to emphasise the importance of WSH to prevent the creation of long-term health problems.

Discussion Once development partners and emergency responders understand these WSH-challenges, they can plan for them. It is important to train all stakeholders in how to include WSH aspects. Also donors need to understand the importance of WSH so that they can accept, if not even demand that WSH is given importance also from a perspective of value for money.

\section{MY TRUTH IS BETTER THAN YOURS - HOW TO FIGHT BACK IN THE AGE OF ALTERNATIVE FACTS}

Jani Ruotsalainen. Cochrane Work Review Group, Finnish Institute of Occupational Health in Kuopio, Finland

\subsection{6/oemed-2018-ICOHabstracts.29}

Apparently we live in the time of post-truth and alternative facts. However, we do not have to take this lying down. What we, the scientific community, can offer is a viable alternative, meaning real facts. There are two things that are critical in this: what to do when faced with outright lies or opinions parading as facts and what to offer in their place. The key to both issues is bias. Alternative facts consciously ignore biases and their effects. Somehow a personal gut feeling just trumps scientific reasoning. The best thing we can do is to accept the existence of biases and to try and minimise their effects in what we do. One way to do this is by means of systematic review. It is a means of abstracting a higher level of truth from multiple scientific studies that each examine a similar issue. Whilst synthesising their results and formulating overall conclusions, one explicitly displays the biases affecting both the existing research (what others have done) and the process of synthesis (what you do to combine the results of the studies in one conclusion).

For example, a Cochrane review found high quality evidence that the use of blunt needles appreciably reduces the risk of exposure to blood and bodily fluids for surgeons and their assistants over a range of operations. High quality evidence means that the finding is not significantly affected by biases in the evidence or in the process to combine their results. Future research is unlikely to change this conclusion. Conversely another Cochrane review found very low quality evidence that bullying behaviours may be prevented in the workplace. Future research is very likely to change this conclusion. Know thyself and be open about your failings. That is a sound basis for true facts.

\section{THE ROLE OF EPIDEMIOLOGICAL RESEARCH IN THE PREVENTION OF OCCUPATIONAL ILL HEALTH}

Lesley Rushton. Imperial College London, London, UK

10.1136/oemed-2018-ICOHabstracts.30

Introduction Concerns about occupationally-related diseases that are rare in the general population have provided an 